\title{
Sustainability and Built Environment: The role of Higher Education in Architecture and Building Engineering
}

\author{
Emilia Conte ${ }^{1}$
}

\begin{abstract}
The sustainability paradigm implies a cultural shift in order to really change the world and society. Education, and specifically higher education, plays the crucial role of preparing students to be not only responsible citizens but also actors and promoters of processes and actions for a sustainable development. This is important in general and even more significant in architecture and engineering fields, as those students will be the designers of the built environment of tomorrow.

This paper draws inspiration from the author's practical experience for more than twenty years in teaching university courses in building technology and sustainable design for undergraduate and graduate students in civil and building engineering, tutoring their stages at professional studios, and supervising their theses. Moving from these premises, the author reports on and discusses some theoretical and practical outcomes concerning the: interpretation of built environment, design process, knowledge related to sustainability, use of a holistic approach in teaching sustainability, and collaboration among professionals. Finally, conclusions sketch potentials of new professionalisms for the sustainable future of built environment.
\end{abstract}

Keywords: Sustainability Education, Built Environment, Building Engineering, Design Process

\section{Introduction}

The introduction of sustainability into everyday life has characterised the world scenario of action since late Eighties of last century. As well-known from scholars across disciplines, sustainability is a multi-faceted concept which escapes a single definition (Little, 2014). This generates multiple interpretations of sustainability often driven from specific interests but always addressed to implement sustainable development in practice. Searching for solutions capable to translate the sustainability paradigm into real implementations has been the driver for soliciting all kinds of actors involved in sustainable development processes: policy-makers, socio-economic entities, scientists and researchers, local stakeholders, common citizens.

This makes evident that the sustainability paradigm implies a cultural shift in order to really change the world and society for a durable development. Among cultural actors in a society, education environments at all levels and specifically higher education play a crucial role (Cortese, 2003). From primary schools to universities, all have soon reacted to the new stimuli posed by sustainability, starting a process of updating teaching programs, subjects of study and curricula. But, the contribution of higher education is 
decisive because universities prepare students not only to be responsible citizens but also to become actors and promoters of processes and actions for a sustainable development. This is very important in general and even more significant in architecture and engineering fields, as those students will be tomorrow's designers of the built environment.

Integrating sustainability in architecture and building engineering courses is much differentiated between regions and countries (Altomonte, 2009; Andamon, Iyer-Raniga, 2013), though global guidelines on education principles, strategies and policies have been traced (UNEP, 2010). Moreover, universities and higher education centres have different capacities to elaborate and applied innovation in them, due to several administrative, scientific and cultural traditions and behaviours. Finally, in the construction field is essential to highlight the large difference which characterises the local production, at national and regional levels, this also influencing educational perspectives and purposes. With such premises about contextualisation clearly in mind, the paper describes a single experience localised at the Polytechnic University in Bari, Italy (hereinafter referred to as poliba.it), where the author works. The local teaching experience is used as a case history useful for tracing the evolution of change due to the introduction of sustainability into education of building engineering university course students, and evaluating its multiple theoretical and practical outcomes.

\section{Case history: teaching@poliba.it}

Sustainability discourse entered the construction field some years later than the introduction of sustainable development into the general arena; particularly, the first definition of sustainable construction dates back to 1994 when it was referred to as "the creation and responsible management of a healthy built environment based on resource efficient and ecological principles" during the First International Conference on Sustainable Construction, in Tampa, Florida (Kibert, 1994). As evident, the attention was focused on environmental aspects of sustainability, this confirming what happened at the time in every field of interest and practical applications. Of course, such specific attention on environmental aspects guided (from then on) the change in professional and production activities related to buildings and constructions, on one side soliciting and on the other side being solicited by research and teaching activities of universities. Below is reported the more than twenty-year experience of the author as a professor at poliba.it, subdivided into periods of five years.

1995-1999. Following the international trend, in the second half of Nineties of last century the author started to introduce the issue of sustainability in the undergraduate and graduate education, mainly by means of orienting the rationale of students' theses and supervising their project works. Synthetically, it can be reported here that the way of working was characterised by a focus on how to design sustainable buildings interpreting sustainability on the base of the more consolidated technical knowledge in the construction field. This was due to the on-going process of a general production of new knowledge on sustainability at that time (CIB, 1999) so that effects of 'potentially' sustainable choices and solutions in building design on the environment, society and 
economy, were not all adequately known and evaluable. Thus, on one side students' works showed features of experimentation and technological innovation, but on the other side they revealed the lack of a systemic vision of a project/design and the emergence of individuality and different reactivity of students in building an interpretation of sustainability in the construction field. We contributed to build new knowledge about sustainability, but it was unstructured.

2000-2004. After this first experience, at the beginning of 2000, the author decided to improve students' knowledge about sustainability introducing the main issues and concerns of sustainable buildings and constructions in the building technology courses she taught at undergraduate level, using sustainability as the essential background of learning and design activities relate to buildings. At the time, knowledge about sustainability got from students at previous levels of their education was few and generic, because schools mainly worked on building perception of the need for sustainable development and maturing awareness and responsibility of future adult citizens. Therefore, the main goal of the author as a professor was to guide building engineering students to translate a general feeling about sustainability, though very important and serious, into an essential way of operating based on a structured knowledge and an openminded vision of sustainability.

At the same time, the author continued to supervise undergraduate and graduate students' theses with a main focus on sustainable buildings and constructions. Technological advancements of the time offered sustainable choices and solutions already tested and then shared in building design (Boonstra et al., 2000). Thus, students' works and projects were characterised by experimenting such choices in a variety of contexts and design situations to enforce their credibility, improve technical (and design) aspects, evaluate their sustainability. Summarising, the commitment was in improving both knowledge and the design process related to sustainability.

Such commitment in teaching, learning, and using a more structured knowledge on sustainability into building design showed to be important and useful for undergraduate students' education but not really effective, because students perceived sustainability and sustainable choices as a way of operating parallel to the most usual, conventional ones: designing using sustainable approach and choices was seen as an exercise to learn because taught in the universities -and then to be studied-and not because it is essential for people and the environment. This was mainly due to the comparison students made between the university environment and the design practice they experimented during their stages at professional studios in architecture and building engineering.

2005-2009. This kind of situation implied more efforts in teaching and practicing sustainability during the following years, mainly aimed at building a systemic view of and using a systemic approach to sustainable design. They can be reported on two levels, undergraduate and graduate/post-graduate education.

At the undergraduate level, students were forced to use a sustainability approach and choose sustainable solutions from the beginning of the design process, i.e. from the initial conception of the design. At the same time, thesis works of students were addressed to enlarge the use of sustainable technologies and solutions for building 
design, creating a sustainable consistent mix which is different for every design work because each building is different from the other. As written above, a main focus for doing such work was to use a systemic view in designing sustainability of buildings.

At the graduate and post-graduate (master) level, students were encouraged to recompose the design activity basing on sustainability and understand that a building is not sustainable because is highly energy efficient or because a lot of sustainable technical- solutions are assembled into design; rather it is sustainable because a sustainability approach permeates the design and is expressed by means of a system of consistent sustainable solutions. Again, the teaching effort was addressed to heavily introduce the systemic view on which sustainability has to be developed trying to avoid to consider sustainability as a fashionable way of acting, and promoting the real value of sustainable choices into design.

This process was also supported by the evolving legislation (Pitt et al., 2009) and the availability of sustainable building evaluation and assessment methods and systems, increasingly developed and used (Ding, 2008), that students could learn and test also during their stages at professional studios. However, while on one side this scenario of action testified the imperative need for sustainability in the construction field, on the other side it risked the systemic vision of sustainable buildings, orienting design choices towards solutions rewarding, for example, in terms of incentives offered by legislation or sustainability 'scores' as calculated by assessment systems. However, designed in this way, implementations towards a sustainable development in the construction field and specifically sustainable buildings have shown that we have neither substantially improved the environment nor society and economy.

From 2010 to present. A vision to overcome such failure can be to shift the focus from one single object, for example the building, to the collection of objects in the built environment, and the interactions between them (Conte, Monno, 2012). Thus, from 2010 to present, at all levels of university education the author as a professor is focusing on principles of complexity and holism in sustainability and how they can be applied in practice.

The lessons provide knowledge of building integrated into the surrounding natural, human and human-made environment and consider its sustainable performances not per se but on the base of a complex system of interactions. To this aim, it is essential to use a holistic approach in teaching sustainability in order to understand that the sustainability content of a building does not correspond to the addition of several but separate sustainable performances, though such behaviour could gain the best sustainability label in assessment systems. Rather, a building -as well as another object in the built environment- is sustainable if it is able to improve the sustainable behaviour of the built environment and people using it.

The design activity developed by students for their undergraduate, graduate and postgraduate work is characterised by a dense knowledge about sustainable solutions and a strong conceptual exercise for contextualising the system of solutions, project by project and place by place. Students are invited to use criticism in relation to what is commonly shared as sustainable in the building and construction field, so to apply a proactive approach to sustainability in the project and improve the design process. Searching for 
appropriate solutions, i.e. sustainable solutions in a specific design rather than standardised, they avoid a passive acceptance of sustainability meaning and point to the overall sustainable performance of the built environment as a whole. To practice such an approach, they are solicited to work in team, helping each other to develop critical abilities and cooperating in design activities.

\section{Learning from the experience}

This over twenty-year teaching experience, accompanied by research activity in sustainable buildings and their evaluation, allows the author to consider some theoretical and practical outcomes concerning sustainability and the built environment, and the role of higher education in forming the tomorrow's professionals in architecture and building engineering. The essential outcomes are synthetically reported in the following.

\section{Interpretation of built environment}

A first reflection concerns the built environment. Difficulties in practicing the sustainable development have determined a fragmentation of sustainable implementations in last decades: sustainable buildings, urban plans, roads, networks, etc. have increased. However, a problem of scale of application for sustainable choices can be detected, i.e. sustainability is interpreted at different scales of application almost not communicating each other. This means that the several objects composing the built environment are - or are considered as- sustainable independently one from the other, as if they are non-interacting. Certainly, this does not represent reality where any choice or decision towards sustainable development has many repercussions in the complex system of interactions between objects and humans in the built environment and, therefore, should be analysed as such.

Consequently, a suggestion is to move the teaching and research focus in sustainability from the scales of single and passive objects to the scale of the built environment, seen as a cross-scalar active entity evolving during time on the base of interactions and their complexity (Monno, Conte, 2015). Following this perspective, we can return to sustainability its dynamic character and contextualise the choices of sustainability in a specific place, time and community, making them more effective. Higher education and research must be able to anticipate the times to promote improvements in society; however, the national and international legislation scenario can support such process, orienting all actors responsible of sustainable development in the built environment. Evaluating sustainability of the built environment can still be a favourable tool for stimulating the change, provided that evaluation methods and assessment systems are capable to interpret and represent the built environment taking into account the complex systems of interactions of its multi-level components.

\section{Design process}

Since its introduction in the field of buildings and constructions, sustainability has much influenced the design process (Gagnon et al., 2012). For example, considering the environmental aspects as the main focus of buildings and constructions, as happened up to now, greening has orienting the design activity towards green performances. Architects 
and building engineering have requested to be increasingly careful to energy saving and efficiency, eco-friendly product use, pollution and waste minimisation, etc. To prove the effectiveness of sustainable design choices, architects and engineers simulate performances of buildings/constructions or their components/parts, using software developed for such purpose and increasingly detailed and specialised. Moreover, good performances, though simulated, become a tool for competing between projects because a building/construction can be positively rated by sustainability assessment systems.

However, the strong focus on performances has increased the lack of a systemic view and complexity when designing components of the built environment, favouring a scalebased approach which mainly considers separate sustainable objects. Thus, it is now necessary to improve the design process focusing attention on the built environment as a whole, with its complexity and dynamics, even when the task is to design a single object as for example a building. This means orienting the design to the reciprocal effects determined by a sustainable object in the built environment and all the other objects as well as people and nature. Surely, this is not an easy task, as it requires architects and engineers the ability to grasp the complex system of interactions for which it is not possible to use the prevalent decomposition of a system in sub-systems and then recompose parts studied and designed separately. The performances to be designed must be those of the built environment as a single dynamic system. Simulation can still be helpful in the design process, but software tools must be developed able to represent interactions and not only isolated performances.

\section{Knowledge related to sustainability}

Sustainability has much challenged also knowledge in the field of buildings and constructions. As reported above, environmental aspects of human activities have largely characterised implementations of sustainable development, from them deriving positive effects for society -for example, health of users of buildings and constructions- and economy -for example, green economy so diffusely promoted worldwide also for opposing the crisis of last years-. All actors involved in the construction process -from researchers to producers, from architects and engineers to constructors, from clients to users- have been pushed to improve the knowledge related to their activities and behaviours. New knowledge on sustainable solutions has been developed together with new sustainable interpretations of traditional solutions. A lot of knowledge is now available and also easily accessible by means of internet; nevertheless, this does not necessarily means an improvement in using that knowledge (Cornell et al., 2013).

In fact, if we consider such scenario of action from the perspective of architects and building engineers, we can recognise that the large knowledge related to sustainability produced and diffused in the building and construction field can be difficult to discern and use, particularly for new professionals not adequately educated and trained. They risk to be guided by solutions better promoted by their manufacturers or to resort to solutions used by others because already tested, without fully understand what sustainability choices they are making and why, i.e. without using a conscious and appropriate approach to their sustainable design. The main negative consequence of this situation is the inability to look at the project as a whole to focus instead on individual parts, though they can be innovative, highly performing, and best rated in sustainability. 
A way to escape this risk is to cultivate critical abilities while learning and using knowledge, supporting this process through collaboration among different expertise.

\section{Holistic approach in teacbing sustainability}

The issues sketched in the above paragraphs explain why it is indispensable to use a holistic approach in teaching sustainability. Differently from the prevalent way of decomposing a system in its parts in order to simplify its representation, analysis and evaluation, a holistic approach allows considering the complex system of interactions in the built environment as a whole, thus improving the design process and recomposing knowledge related to sustainability. The need for using holism and its philosophical basis in education for sustainability is not new, particularly with regard to environmental education in sustainability (Tilbury, 1995); but, a related problem is how to put it into practice, specifically for education and training in sustainability of architects and engineers where a reductionist approach usually prevails in order to build skills in problem-solving.

Professors and higher education institutions are responsible to guide the cultural shift posed by sustainability, creating new paradigms for architects and engineers education responding to intellectual challenges of complexity and multidisciplinary, development and implementation of technologies from the micro to the macro-level, holism vs reductionism in order to address "social needs and priorities linking social, economic, environmental, legal and political considerations with technological design and innovation" (Duderstadt, 2010 p. 20). Architects and engineers of tomorrow must be prepared to: cooperate rather than compete; develop inclusive decision-making activities rather than narrow problem-solving to isolated objects in the built environment; manage a rich, ample, detailed and evolving knowledge and produce critical syntheses rather than endless analyses; develop and use technologies and innovations for designing and constructing a real sustainable built environment everywhere and every time, rather than producing decontextualised though symbolic sustainable buildings or constructions. Sustainability ethics and culture must characterise design education (Keirl, 2015), as well as the design activities of the tomorrow's professionals.

\section{Cooperation among professionals}

The cultural shift required by sustainability -the need to work with a holistic approach, the capacity to connect the local to the global, the ability to recompose knowledge, the skill in using technologies and innovations- directs architects and engineers to cooperate between themselves and other actors of development processes in order to produce a sustainable built environment. Actually, it is almost frequent that professionals in building and construction field collaborate in team, in search for design solutions based on different expertise and evaluated under the many aspects of a project. So developed, projects are often more competitive thus rewarding collaboration in team. However, designing in team is not easy for many reasons, starting from the basic problem of languages used to describe the object of design that usually differ between professionals. The intense commitment to BIM (Building Information Modelling) in recent years(Azhar, 2011) shows the need to improve team communications during the design and construction process. 
Beyond communication, there are problems of different scales of design, specific competences, general and detailed knowledge, that affect interactions between professionals and jeopardise design results. Therefore, a team leader is often necessary to guarantee consistency of the project. This modus operandi limits the potential of cooperation, which on the contrary is based on exploiting skills and expertise of all participants in the process and aims at discovering original solutions that none of the participants is capable to produce alone. It is therefore necessary to train architects and engineers also to a cooperative behaviour in performing their professional activities. This is not only a question of BIM or other software tools, though they can be very supportive, but rather of sharing methods and approaches.

\section{Conclusions}

Architects and engineers have always played an important role in society, interpreting its needs and producing the built environment for human development. This role has weakened over the years when profit-based development models have led to emergence of design solutions that are standardised, decontextualised and inattentive to both the natural environment and humans. The sustainability paradigm exhorts architects and engineers to a tension towards a sustainable future, which implies new skills and expertise and then a new way of practicing their profession.

In the building and construction field, architects and engineers must have new abilities useful for regenerating the unsustainable built environment of today. To usual technical skills, they have to add the capacity to understand the complex system of interactions characterising the built environment and make design decisions that address sustainability as a property to be developed in the built environment as an active whole. Nature, buildings, networks, people are all interconnected and their functioning as built environment can be sustainable over time only if it is properly considered that they interact. After almost four decades of efforts in implementing sustainability, we are now conscious that no sustainable solutions can effectively and durably work if they are decided upon or versus people (Bay, 2010). From waste collection to transportation choices, from energy saving to water recycling, people's behaviour is essential for matching sustainable implementations: it is not only a matter of acceptance, but rather of awareness, active participation, continuous involvement and even promotion of sustainability. The design process is greatly challenged to change to produce a real sustainable development.

Critical abilities, transboundary competences (Lansu et al., 2013), holistic approach are essential characteristics that architects and engineers must have and perform in order to activate cooperation, so to stimulate the creation of sustainable solutions, which can express innovation addressing technological advancements experimentation and at the same time be suitable and effective for a sustainable regeneration of the built environment. Higher education has the responsibility to strongly support the process of training new professionalisms for such a sustainable future. 


\section{References}

Altomonte, S. (2009). Environmental Education for Sustainable Architecture. Review of European Studies,1(2), $12-21$.

Andamon, M. M., Iyer-Raniga, U. (2013). Innovation in integrating sustainability education into engineering and built environment curriculum: the case for Asia-Pacific. In P. Hájek, J. Tywoniak, A Lupíšek, J. Růžička, K. Sojková (Eds), Proceedings ofCESB13 -Central Europe towards Sustainable Building 2013. Prague, 26-28 June 2013. Retrieved from http://www.cesb.cz/cesb13/proceedings/6 education/CESB13 1206.pdf [Accessed 13 June 2016].

Azhar, S. (2011). Building Information Modeling (BIM): Trends, Benefits, Risks, and Challenges for the AEC Industry. Leadership and Management in Engineering 11(3), 241-252.

Bay, J. H. (2010). Towards a Fourth Ecology: Social and Environmental Sustainability with Architecture and Urban Design. Journal of Green Building5(4), 176-197.

Boonstra, C., Rovers, R., Pauwels, S. (Eds, 2000). Proceedings of the International Conference Sustainable Building 2000. Maastricht, The Netherlands, 22-25 October 2000.

CIB (1999). Agenda 21 on sustainable construction. CIB Report Publication 237. Retrieved from http://cic.vtt.fi/eco/cibw82/A21 text.pdf [Accessed 13 June 2016].

Conte, E., Monno, V. (2012). Beyond the buildingcentric approach: A vision for an integrated evaluation of sustainable buildings. Environmental Impact Assessment Review, 34, 31-40.

Cornell, S., Berkhout, F., Tuinstra, W., et alii (2013). Opening up knowledge systems for better responses to global environmental change. Environmental Science \& Policy, 28, 60-70.

Cortese, A.D. (2003). The Critical Role of Higher Education in Creating a Sustainable Future. Planning for Higher Education, 31(3), 15-22.

Ding, G.K. C. (2008). Sustainable construction - The role of environmental assessment tools. Journal of Environmental Management, 86(3), 451-464.

Duderstadt, J. J. (2010). Engineering for a Changing World. A Roadmap to the Future of American Engineering. Practice, Research and Education. In D. Grasso, M. B. Burkins (Eds.), Holistic Engineering Education. Beyond Technology (pp. 17-35). New York, Dordrecht, Heidelberg, London: Springer.

Gagnon, B., Leduc, R., Savard, L. (2012). From a conventional to a sustainable engineering design process: different shades of sustainability. Journal of Engineering Design, 23(1), 49-74.

Keirl, S. (2015). Global Ethics, Sustainability, and Design and Technology Education. In K. Stables, S. Keirl (Eds), Environment, Ethics and Cultures. Design and Technology Education's Contribution to Sustainable Global Futures(pp. 33-52). Rotterdam, The Netherlands: Sense Publishers.

Kibert, C. J. (Ed, 1994). Proceedings of the First International Conference on Sustainable Construction. Tampa, Florida, 6-9 November 1994.

Lansu, A., Boon, J., Sloep, P. B., van Dam-Mieras, R. (2012). Changing professional demands in sustainable regional development: a curriculum design process to meet transboundary competence. Journal of Cleaner Production, 49, 123-133.

Little, D. L. (2014). Defining Sustainability in Meaningful Ways for Educators. Journal of Sustainability Education, 7. Retrieved from http://www.jsedimensions.org/wordpress/wpcontent/uploads/2014/12/Little-JSE-Vol-7-Dec-2014.pdf [Accessed 13 June 2016].

Monno, V., Conte, E. (2015). Sustainability in the built environment: integrating scales of action and evaluation. European Journal of Sustainable Development, 4(2), 51-60.

Pitt, M., Tucker, M., Riley, M., Longden, J. (2009). Towards sustainable construction: promotion and best practices. Construction Innovation, 9(2), 201-224.

Tilbury, D. (1995). Environmental Education for Sustainability: defining the new focus of environmental education in the 1990s. Environmental Education Research, 1(2), 195-212.

UNEP (2010). Guidelines on Education Policy for Sustainable Built Environments. Retrieved from http://www.unep.org/sbci/pdfs/UNEPSBCI EducationPolicyGuidelines 2010.pdf [Accessed 13 June 2016]. 
